\title{
A water-soluble extract from cultured medium of Ganoderma lucidum (Reishi) mycelia attenuates the small intestinal injury induced by anti-cancer drugs
}

\author{
NAOKI KASHIMOTO ${ }^{1}$, SATOMI ISHII ${ }^{1}$, YUKI MYOJIN ${ }^{2}$, MITSUYASU USHIJIMA ${ }^{1}$, \\ MINORU HAYAMA ${ }^{1}$ and HIROMITSU WATANABE ${ }^{2}$ \\ ${ }^{1}$ Health Care Institute, Wakunaga Pharmaceutical Co Ltd., Hiroshima 739-1195; \\ ${ }^{2}$ Department of Experimental Oncology, Research Institute for \\ Radiation Biology and Medicine, Hiroshima University, Hiroshima 734-8553, Japan
}

Received July 13, 2009; Accepted September 30, 2009

DOI: 10.3892/ol_00000011

\begin{abstract}
The present study investigated whether a watersoluble extract from the culture medium of Ganoderma lucidum (Reishi) mycelia (MAK) is able to protect the small intestine against damage induced by anti-cancer drugs. Six-week-old male B6C3F1/Crlj mice were fed a basal diet (MF) alone or with various doses of MAK or Agarics blazei Murrill (AGA) beginning one week before treatment with the anti-cancer drugs. Mice were sacrificed 3.5 days after injection of the anti-cancer drug, the small intestine was removed and tissue specimens were examined for the regeneration of small intestinal crypts. In experiment 1 , the number of regenerative crypts after the administration of 5-fluorouracil $(5 \mathrm{FU})$ intravenously $(250 \mathrm{mg} / \mathrm{kg})$ or intraperitoneally (250 or $500 \mathrm{mg} / \mathrm{kg}$ ) was compared after treatment with MAK or AGA. MAK protected against 5FU-induced small intestinal injury whereas AGA did not. In experiment 2, we investigated the protective effect of MAK against small intestinal injury induced by the anti-cancer drugs: UFT (tegafur with uracil; $1,000 \mathrm{mg} / \mathrm{kg}$, orally), cisplatin (CDDP; 12.5 and $25 \mathrm{mg} /$ $\mathrm{kg}$, intraperitoneally), cyclophosphamide (CPA; $250 \mathrm{mg} / \mathrm{kg}$, orally) and gefitinib (Iressa; 2,000 and 4,000 mg/kg, orally). UFT and CDDP decreased the number of regenerative crypts, but treatment with MAK attenuated the extent of UFT- or CDDP-induced small intestinal injury. CPA or Iressa plus MAK up-regulated crypt regeneration. The present results indicate that MAK ameliorates the small intestinal injury caused by several anti-cancer drugs, suggesting that MAK is a potential preventive agent against this common adverse effect of chemotherapy.
\end{abstract}

Correspondence to: Dr Naoki Kashimoto, Health Care Institute, Wakunaga Pharmaceutical Co. Ltd., 1624 Shimokoutachi, Koda-cho, Akitakata, Hiroshima 739-1195, Japan

E-mail: kashimoto_n@wakunaga.co.jp

Key words: small intestinal injury, anti-cancer drugs, Ganoderma lucidum, B6C3F1 mice

\section{Introduction}

Ganoderma lucidum (Fr.) Karst. (Polyporaceae) is a medicinal mushroom known to the Japanese as 'Rei-shi' or 'Mannentake', and to the Chinese as 'Lingzhi'. Its fruiting bodies have been used for their medicinal properties in traditional Chinese medicine for over 2,000 years. The use of this mushroom for promotion of vitality and as an anti-aging agent is described in detail in the classic compendium of traditional Chinese medicine Shen Nung Ben Cao Jin (dated 206 B.C. - 8 A.D.). Furthermore, Ganoderma lucidum (G. lucidum) was used more recently in China and other oriental countries for the treatment of debility and weakness, hypertension, cardiovascular disease, bronchitis, arthritis, neurasthenia, insomnia, hepatopathy, chronic hepatitis, nephritis, gastric ulcer, asthma, diabetes, altitude sickness, AIDS and cancer (1-3). Of particular interest among the reported biological/pharmacological properties of G. lucidum are its anti-tumor activities, including cell cycle arrest, induction of apoptosis, inhibition of motility, anti-angiogenesis and anti-mutagenesis (3-9). The fruiting bodies and the mycelium of the mushroom have very similar compositions, but the mycelium contains several additional nutrients and beneficial components. Thus, the mycelium is considered to be the 'essence' of the mushroom organism and is consumed as a functional food. The use of mycelia of Ganoderma as a 'designer food' means that culture techniques for this organism are well established.

A water-soluble extract from the culture medium of G. lucidum (Rei-shi) mycelia (MAK) after fermentation on a solid medium containing bagasse contains various types of substances, such as polysaccharides, proteins, water-soluble lignin and triterpenes. Previously, we reported that MAK shows preventive effects on the development of chemical carcinogen-induced aberrant crypt foci, colon adenomas, colon tumors and pulmonary adenocarcinomas in rats (10-13). Furthermore, we reported that MAK has protective effects against $\mathrm{X}$-irradiation-induced small intestinal injury in mice (14). Many of the adverse effects of anti-cancer drugs also arise from the ability of these drugs to inhibit DNA synthesis and cell division in normal cells. Thus, we hypothesized that 
Table I. Body and organ weights (relative weights).

\begin{tabular}{llllllr}
\hline Group & BW $(\mathrm{g})$ & Spleen $(\mathrm{mg})$ & Liver $(\mathrm{g})$ & Thymus $(\mathrm{mg})$ & Kidney $(\mathrm{g})$ & Testis $(\mathrm{g})$ \\
\hline Normal & $23.1 \pm 1.1$ & $0.090 \pm 0.019$ & $1.37 \pm 0.09$ & $0.044 \pm 0.009$ & $0.39 \pm 0.02$ & $0.149 \pm 0.011$ \\
$5 \%$ MAK & $23.6 \pm 0.6^{\mathrm{a}}$ & $0.095 \pm 0.017^{\mathrm{a}}$ & $1.48 \pm 0.10^{\mathrm{a}}$ & $0.050 \pm 0.009^{\mathrm{a}}$ & $0.41 \pm 0.03^{\mathrm{a}}$ & $0.148 \pm 0.017$ \\
5\% AGA & $24.1 \pm 1.6^{\mathrm{a}}$ & $0.111 \pm 0.037^{\mathrm{a}}$ & $1.48 \pm 0.12^{\mathrm{a}}$ & $0.062 \pm 0.008^{\mathrm{a}}$ & $0.41 \pm 0.03^{\mathrm{a}}$ & $0.152 \pm 0.007$ \\
5FU + MF & $21.1 \pm 1.5^{\mathrm{c}}$ & $0.038 \pm 0.006^{\mathrm{c}}$ & $1.18 \pm 0.16^{\mathrm{c}}$ & $0.028 \pm 0.012^{\mathrm{d}}$ & $0.32 \pm 0.02^{\mathrm{d}}$ & $0.127 \pm 0.019$ \\
5FU + 5\% MAK & $21.3 \pm 1.2$ & $0.042 \pm 0.003$ & $1.19 \pm 0.09$ & $0.022 \pm 0.004$ & $0.34 \pm 0.02$ & $0.114 \pm 0.027$ \\
5FU + 5\% AGA & $21.6 \pm 0.8$ & $0.045 \pm 0.004$ & $1.26 \pm 0.10$ & $0.027 \pm 0.009$ & $0.36 \pm 0.03^{\mathrm{b}}$ & $0.134 \pm 0.023$ \\
5FU + 2.5\% MAK & $21.6 \pm 1.2$ & $0.042 \pm 0.004$ & $1.21 \pm 0.05$ & $0.027 \pm 0.005$ & $0.36 \pm 0.04^{\mathrm{b}}$ & $0.132 \pm 0.019$ \\
5FU + 2.5\% AGA & $21.4 \pm 1.6$ & $0.045 \pm 0.005$ & $1.25 \pm 0.17$ & $0.014 \pm 0.005$ & $0.36 \pm 0.02^{\mathrm{b}}$ & $0.133 \pm 0.018$ \\
5FU + 1.25\% MAK & $22.3 \pm 0.6$ & $0.042 \pm 0.002$ & $1.22 \pm 0.05$ & $0.019 \pm 0.007$ & $0.36 \pm 0.01^{\mathrm{b}}$ & $0.127 \pm 0.021$ \\
5FU + 1.25\% AGA & $22.9 \pm 0.5$ & $0.047 \pm 0.004$ & $1.28 \pm 0.06$ & $0.027 \pm 0.012$ & $0.39 \pm 0.01^{\mathrm{a}}$ & $0.147 \pm 0.005$ \\
\hline
\end{tabular}

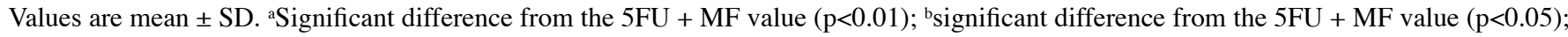
${ }^{\mathrm{c}}$ significant difference from the normal value $(\mathrm{p}<0.05)$; ${ }^{\mathrm{d}}$ significant difference from the normal value $(\mathrm{p}<0.01)$.

MAK is able to protect against small intestinal injury after chemotherapy. The present study was conducted to assess the effects of MAK and Agarics blazei on small intestinal injury after the administration of various types of anti-cancer drugs.

\section{Materials and methods}

Animals. Two hundred and thirty 6-week-old male B6C3F1/ Crlj mice (Charles River Japan, Inc.) were used in the present study. They were housed five to a polycarbonate cage and kept under constant conditions of temperature $\left(24 \pm 2^{\circ} \mathrm{C}\right)$ and relative humidity $(55 \pm 10 \%)$ with a 12 -h light/dark cycle. The animals were maintained in accordance with the 'Guidelines for the Care and Use of Laboratory Animals' established by the Hiroshima University and fed a commercial diet (Oriental Yeast Co. Ltd., Tokyo, Japan) alone or with a 1.25, 2.5 or $5.0 \%$ (w/w) supplement of MAK or AGA. Normal tap water was also provided ad libitum.

Anti-cancer drugs. Anti-cancer drugs were obtained as follows: 5FU (5-FU injection 250 Kyowa; Kyowa Hakko Co., Ltd., Tokyo, Japan), UFT (prepared by Taiho Pharmaceutical Co., Ltd., Tokyo, Japan), CDDP (Randa injection; Nippon Kayaku Co., Ltd., Tokyo, Japan), CPA (Endoxan; Shionogi Pharmaceutical Co., Ltd., Osaka, Japan) and Iressa (Iressa tablets 250; AstraZeneca K.K., Osaka, Japan).

G. lucidum mycelia and Agarics blazei. A water-soluble extract from the culture medium of MAK was prepared by Noda Shokkin-Kogyo Co., Ltd. (Chiba, Japan). In brief, MAK were cultured in a solid medium composed mainly of sugarcane bagasse for three months. The whole medium containing the mycelia was then extracted with hot water. The extract was filtered and spray-dried to obtain MAK. Agarics was purchased as a commercial powder of Agarics blazei Murrill.

Autopsy. Mice were sacrificed 3.5 days after injection of the anti-cancer drugs. Immediately after sacrifice, segments of the jejunum from the ileum junction $(30-40 \mathrm{~cm})$ were removed and fixed in Carnoy's solution. The segments were cut into several pieces, bundled together, embedded in paraffin, sectioned at a thickness of $3 \mu \mathrm{m}$ and stained with hematoxylin and eosin. To quantify regenerating crypts, the number of crypts/circumference was determined in cross-section. In each mouse, the number of regenerative crypts in 10 gut cross-sections was scored.

Experiment 1. This was a comparative study of the ability of MAK and AGA to attenuate the small intestinal injury induced by $5 \mathrm{FU}$. Mice were fed a basal diet (MF) alone or with 1.25 , 2.5 or $5.0 \%$ of MAK or AGA beginning one week prior to treatment with the anti-cancer drug, which was administered intravenously (i.v.) $(250 \mathrm{mg} / \mathrm{kg})$ or intraperitoneally (i.p.) ( 250 or $500 \mathrm{mg} / \mathrm{kg}$ ). At 3.5 days after the administration of $5 \mathrm{FU}$, the mice were sacrificed. Body weight and organ weights of thymus, liver, kidney, spleen and testis were recorded, and the number of regenerative crypts of the small intestine was measured as described above.

Experiment 2. This was a study of the protective effect of MAK on small intestinal injury induced by several anti-cancer drugs. At one week after initiation of treatment with MAK, the anti-cancer drugs were administered as follows: CPA was given orally (p.o.; $250 \mathrm{mg} / \mathrm{kg}$ ), i.p. (200 mg/kg) and subcutaneously (s.c.; $150 \mathrm{mg} / \mathrm{kg}$ ). Iressa was p.o. as one dose $(2,000 \mathrm{mg} /$ $\mathrm{kg}$ ) or as two doses $(4,000 \mathrm{mg} / \mathrm{kg})$ with a 2-h interval between the doses. Mice were sacrificed at 3.5 days after the administration of each anti-cancer drug. Body and organ weights and the number of regenerative crypts were measured.

Statistical analysis. Statistical significance was determined by Dunnett's method for multiple comparisons.

\section{Results}

Experiment 1: Comparative study of the ability of MAK and AGA to attenuate $5 F U$-induced small intestinal injury. The administration of $5 \mathrm{FU}(250 \mathrm{mg} / \mathrm{kg}$, i.v.) resulted in body weight and organ weight loss in spleen, liver, thymus and kidney, but not in testis (Table I). Treatment with MAK and AGA did not 
Table II. Number of regenerative crypts.

\begin{tabular}{lccc}
\hline Group & $250 \mathrm{mg} / \mathrm{kg}$ i.v. & $250 \mathrm{mg} / \mathrm{kg}$ i.p. & $500 \mathrm{mg} / \mathrm{kg}$ i.p. \\
\hline Normal & $110.2 \pm 8.9^{\mathrm{a}}$ & $100.6 \pm 10.5^{\mathrm{a}}$ & $100.6 \pm 10.5^{\mathrm{a}}$ \\
$5 \%$ MAK & $112.9 \pm 12.2$ & $100.5 \pm 9.2$ & $100.5 \pm 9.2$ \\
$5 \%$ AGA & $116.2 \pm 13.6$ & $103.7 \pm 10.0$ & $103.7 \pm 10.0$ \\
$5 F U+$ MF & $83.7 \pm 11.2$ & $89.1 \pm 11.0$ & $67.7 \pm 8.2$ \\
$5 F U+5 \%$ MAK & $97.0 \pm 9.9^{\mathrm{a}}$ & $106.6 \pm 16.6^{\mathrm{a}}$ & $83.4 \pm 7.9^{\mathrm{a}}$ \\
5FU + 5\% AGA & $82.0 \pm 9.5$ & $80.4 \pm 8.4$ & $73.6 \pm 10.7$ \\
5FU + 2.5\% MAK & $110.3 \pm 14.3^{\mathrm{a}}$ & $116.5 \pm 14.3^{\mathrm{a}}$ & $82.8 \pm 7.9^{\mathrm{a}}$ \\
5FU + 2.5\% AGA & $87.6 \pm 14.9$ & $89.6 \pm 11.2$ & $70.9 \pm 8.1$ \\
5FU + 1.25\% MAK & $113.6 \pm 15.0^{\mathrm{a}}$ & $118.1 \pm 15.3^{\mathrm{a}}$ & $71.2 \pm 9.5$ \\
5FU + 1.25\% AGA & $85.5 \pm 9.9$ & $87.3 \pm 10.8$ & $73.4 \pm 7.9$ \\
\hline
\end{tabular}

Values are mean \pm SD. a Significant difference from the 5FU + MF value $(\mathrm{p}<0.01)$; i.v., intravenously; i.p., intraperitoneally.

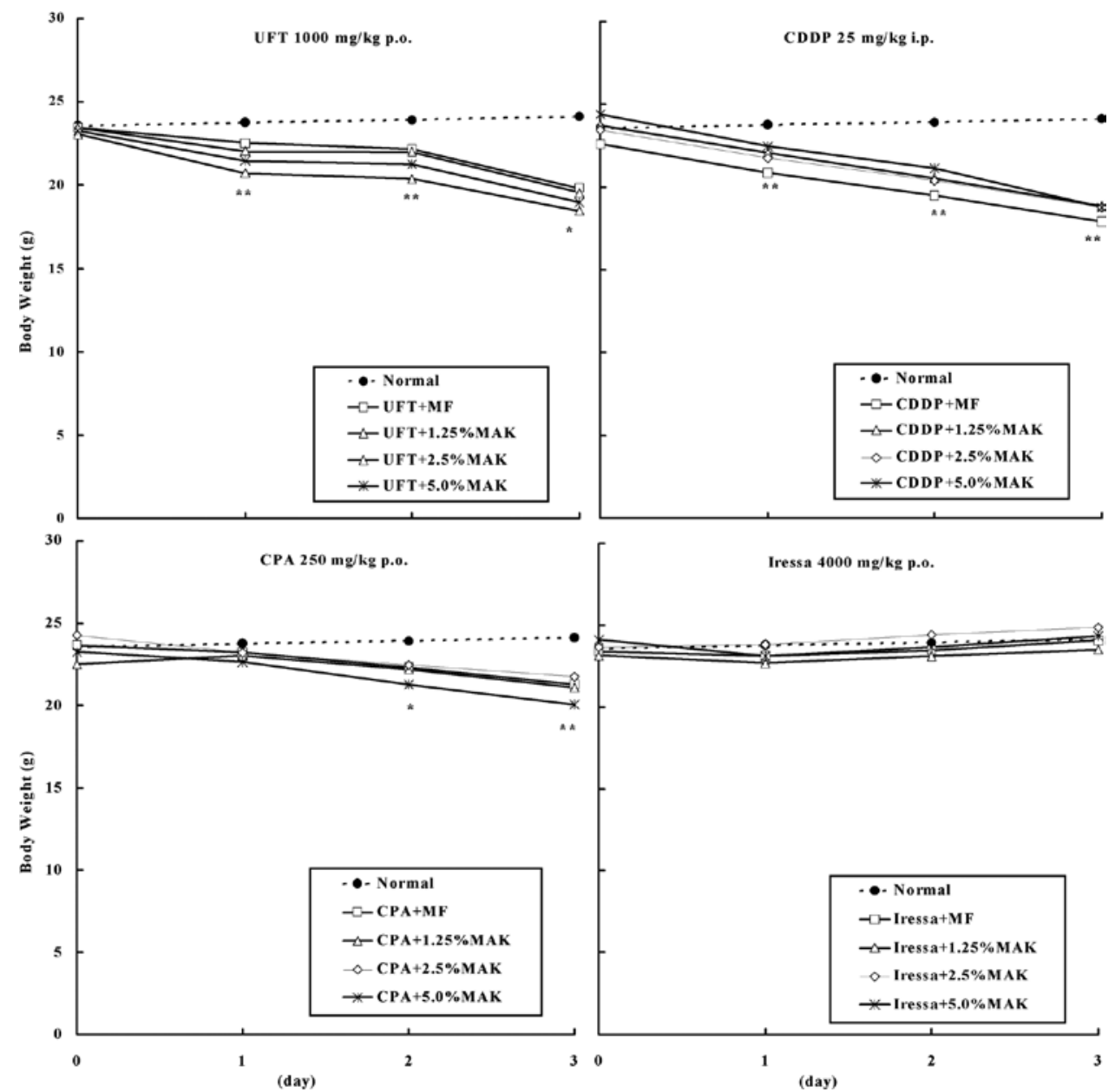

Figure 1. Effect of several anti-cancer drugs with or without MAK treatment on body weight in mice. Body weights were monitored daily for 3 days after the administration of individual anti-cancer drugs. Asterisks indicate significant differences between the individual anti-cancer drug + MF group vs. the normal group $\left({ }^{*} \mathrm{p}<0.05,{ }^{* *} \mathrm{p}<0.01\right)$.

affect these weight losses, except that kidney weight loss was attenuated in the $5 \mathrm{FU}+\mathrm{MAK}$ and $5 \mathrm{FU}+$ AGA groups, with the exception of $5 \mathrm{FU}+5 \% \mathrm{MAK}$.

Small intestine tissue specimens were prepared and counted for the number of regenerative crypts (Table II).
The administration of $5 \mathrm{FU}$ ( $250 \mathrm{mg} / \mathrm{kg}$, i.v.) significantly decreased the number of regenerative crypts compared with the normal group $(83.7 \pm 11.2$ vs. $110.2 \pm 8.9, \mathrm{p}<0.01)$. The $5 \mathrm{FU}$ + MAK groups showed a significant increase compared with the 5FU-alone group $(\mathrm{p}<0.01)$, whereas treatment with 
Table III. Effect of MAK on crypt regeneration after administration of several anti-cancer drugs.

\begin{tabular}{ccc}
\hline Group & $\begin{array}{c}\text { No. of regenerative } \\
\text { crypts }\end{array}$ & $\begin{array}{r}\text { Increased } \\
\text { rate }(\%)\end{array}$ \\
\hline
\end{tabular}

\section{UFT $1,000 \mathrm{mg} / \mathrm{kg}$ p.o.}

$\begin{array}{lc}\text { Normal } & 107.6 \pm 10.4 \\ \text { UFT + MF } & 65.8 \pm 8.1 \\ \text { UFT + } 1.25 \% \text { MAK } & 80.6 \pm 11.4^{\mathrm{a}} \\ \text { UFT + } 2.5 \% \text { MAK } & 94.2 \pm 11.5^{\mathrm{a}} \\ \text { UFT }+5.0 \% \text { MAK } & 102.7 \pm 12.5^{\mathrm{a}}\end{array}$

CDDP $12.5 \mathrm{mg} / \mathrm{kg}$ i.p.

Normal

$\mathrm{CDDP}+\mathrm{MF}$

$\mathrm{CDDP}+1.25 \% \mathrm{MAK}$

$\mathrm{CDDP}+2.5 \% \mathrm{MAK}$

$\mathrm{CDDP}+5.0 \% \mathrm{MAK}$

CDDP $25 \mathrm{mg} / \mathrm{kg}$ i.p.

Normal
$\mathrm{CDDP}+\mathrm{MF}$
$\mathrm{CDDP}+1.25 \% \mathrm{MAK}$
$\mathrm{CDDP}+2.5 \% \mathrm{MAK}$
$\mathrm{CDDP}+5.0 \% \mathrm{MAK}$

CPA $250 \mathrm{mg} / \mathrm{kg}$ p.o.

Normal

$\mathrm{CPA}+\mathrm{MF}$

$\mathrm{CPA}+1.25 \% \mathrm{MAK}$

$\mathrm{CPA}+2.5 \% \mathrm{MAK}$

$\mathrm{CPA}+5.0 \% \mathrm{MAK}$

CPA 200 mg/kg i.p.

Normal

$\mathrm{CPA}+\mathrm{MF}$

$\mathrm{CPA}+1.25 \% \mathrm{MAK}$

$\mathrm{CPA}+2.5 \% \mathrm{MAK}$

$\mathrm{CPA}+5.0 \% \mathrm{MAK}$

CPA $150 \mathrm{mg} / \mathrm{kg}$ s.c.

Normal

$\mathrm{CPA}+\mathrm{MF}$

$\mathrm{CPA}+1.25 \% \mathrm{MAK}$

$\mathrm{CPA}+2.5 \% \mathrm{MAK}$

$\mathrm{CPA}+5.0 \% \mathrm{MAK}$

Iressa $2,000 \mathrm{mg} / \mathrm{kg}$ p.o.

Normal

Iressa + MF

Iressa $+1.25 \%$ MAK

Iressa $+2.5 \%$ MAK

Iressa $+5.0 \%$ MAK

Iressa 4,000 mg/kg p.o.

Normal

Iressa + MF

Iressa $+1.25 \%$ MAK

Iressa $+2.5 \%$ MAK

Iressa $+5.0 \%$ MAK
$107.6 \pm 10.4$

$89.8 \pm 11.7$

$117.4 \pm 16.7^{\mathrm{a}}$

$121.7 \pm 12.6^{\mathrm{a}}$

$118.4 \pm 14.6^{\mathrm{a}}$

$108.0 \pm 13.9$

$9.5 \pm 4.4$

$21.9 \pm 4.7^{\mathrm{a}}$

$26.6 \pm 5.3^{\mathrm{a}}$

$32.5 \pm 3.4^{\mathrm{a}}$

$110.5 \pm 12.6$

$120.9 \pm 12.1$

$136.6 \pm 13.8^{\mathrm{a}}$

$148.7 \pm 15.0^{\mathrm{a}}$

$150.0 \pm 14.7^{\mathrm{a}}$

$107.4 \pm 9.7$

$135.5 \pm 13.6$

$145.1 \pm 16.3^{\mathrm{a}}$

$147.0 \pm 17.4^{\mathrm{a}}$

$152.2 \pm 17.2^{\mathrm{a}}$

\section{$107.4 \pm 9.7$}

$117.8 \pm 14.9$

$130.4 \pm 13.8^{a}$

$150.6 \pm 17.0^{\mathrm{a}}$

$160.4 \pm 17.1^{\text {a }}$

$108.0 \pm 13.9$

$107.5 \pm 11.7$

$117.8 \pm 10.6^{\mathrm{a}}$

$119.9 \pm 13.7^{\mathrm{a}}$

$123.6 \pm 14.7^{\mathrm{a}}$

$110.5 \pm 12.6$

$110.0 \pm 11.8$

$132.2 \pm 15.5^{\mathrm{a}}$

$151.5 \pm 16.9^{\mathrm{a}}$

$161.5 \pm 19.8^{a}$
$5 \mathrm{FU}+\mathrm{AGA}$ did not affect the number of regenerative crypts $(82.0 \pm 9.5$ to $87.6 \pm 14.9)$. The number of regenerative crypts significantly decreased after treatment with $5 \mathrm{FU}(250 \mathrm{mg} /$ $\mathrm{kg}$, i.p.) compared with the normal group $(89.1 \pm 11.0$ vs. $100.6 \pm 10.5, \mathrm{p}<0.01)$. Again, the number of regenerative crypts in the $5 \mathrm{FU}+\mathrm{MAK}$ groups $(106.6 \pm 16.6$ to $118.1 \pm 15.3)$ was significantly higher than that in the 5FU-alone group $(\mathrm{p}<0.01)$, whereas treatment with 5FU + AGA did not affect the number of regenerative crypts $(80.4 \pm 8.4$ to $89.6 \pm 11.2)$. Administration of $5 \mathrm{FU}(500 \mathrm{mg} / \mathrm{kg}$, i.p.) resulted in a significant decrease in the number of regenerative crypts compared with the normal group $(67.7 \pm 8.2$ vs. $100.6 \pm 10.5, \mathrm{p}<0.01)$. This decrease in the number of regenerative crypts was significantly attenuated in the $5 \mathrm{FU}+5 \% \mathrm{MAK}$ and $5 \mathrm{FU}+2.5 \%$ MAK groups compared with the 5FU-alone group $(83.4 \pm 7.9$ and $82.8 \pm 7.9, \mathrm{p}<0.01)$, whereas the $5 \mathrm{FU}+\mathrm{AGA}$ and $5 \mathrm{FU}+1.25 \%$ MAK groups showed no such effect $(70.9 \pm 8.1$ to $73.6 \pm 10.7)$. Small intestinal crypt regeneration was unaffected by MAK or AGA alone.

Experiment 2: Protective effect of MAK on small intestinal injury induced by several anti-cancer drugs. Fig. 1 shows body weight changes of mice administered with UFT $1,000 \mathrm{mg} / \mathrm{kg}$ (p.o.), CDDP $25 \mathrm{mg} / \mathrm{kg}$ (i.p.), CPA $250 \mathrm{mg} /$ $\mathrm{kg}$ (p.o.) or Iressa $4,000 \mathrm{mg} / \mathrm{kg}$ (p.o.). The administration of UFT or CDDP decreased the body weight from the following day, and administration of CPA decreased body weight after 2 days, whereas the administration of Iressa had no effect on body weight. Treatment with MAK did not alter the body weight loss or gain associated with administration of these anti-cancer drugs.

Tissue specimens of the groups were prepared and counted to assess the number of regenerative crypts (Table III). Following administration of UFT $(1,000 \mathrm{mg} / \mathrm{kg}$, p.o.), the number of regenerative crypts significantly decreased compared with the normal group (65.8 \pm 8.1 vs. 107.6 \pm 10.4 , $\mathrm{p}<0.01)$. At all dose levels, treatment with MAK significantly increased the number of regenerative crypts compared with the UFT-alone group $(80.6 \pm 11.4$ to $102.7 \pm 2.5$, a $22.5-56.1 \%$ up-regulation compared with UFT + MF, $\mathrm{p}<0.01)$. Following administration of CDDP $(12.5 \mathrm{mg} / \mathrm{kg}$, i.p.), the number of regenerative crypts significantly decreased compared with the normal group $(89.8 \pm 11.7$ vs. $107.6 \pm 10.4, \mathrm{p}<0.01)$. The number of regenerative crypts in the CDDP + MAK groups showed a significant increase compared with the CDDP-alone group (117.4 \pm 16.7 to $121.7 \pm 12.6$, a $30.7-35.4 \%$ up-regulation compared with CDDP + MF; $\mathrm{p}<0.01)$. The number of regenerative crypts after administration of CDDP $(25.0 \mathrm{mg} /$ $\mathrm{kg}$, i.p.) showed a significant decrease compared with the normal group $(9.5 \pm 4.4$ vs. $108.0 \pm 13.9, \mathrm{p}<0.01)$. The number of regenerative crypts in the CDDP + MAK groups significantly increased compared with the CDDP-alone group $(21.9 \pm 4.7$ to $32.5 \pm 3.4$, a $130.5-242.1 \%$ up-regulation vs. CDDP + MF; $\mathrm{p}<0.01)$. Following administration of CPA $(250 \mathrm{mg} / \mathrm{kg}$, p.o.), the number of regenerative crypts significantly increased compared with the normal group $(120.9 \pm 12.1$ vs. $110.5 \pm 12.6$, $\mathrm{p}<0.01)$ and this up-regulation was further increased by treatment with MAK $(136.6 \pm 13.8$ to $150.0 \pm 14.7$, a $13.0-24.1 \%$ increase vs. $\mathrm{CPA}+\mathrm{MF}, \mathrm{p}<0.01)$. The number of regenerative crypts after administration of CPA (200 mg/kg, i.p.) showed a significant increase compared with the normal group

Values are mean $\pm \mathrm{SD}$; p.o., given orally; i.p., intraperitoneally; s.c.

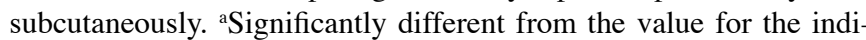
vidual anti-cancer drug + MF group $(p<0.01)$; ${ }^{\text {b percentage increase }}$ from the value for the individual anti-cancer drug + MF group. 
$(135.5 \pm 13.6$ vs. $107.4 \pm 9.7, \mathrm{p}<0.01)$ and again this up-regulation was further increased by treatment with MAK $(145.1 \pm 16.3$ to $152.2 \pm 17.2$, a $7.1-12.3 \%$ increase vs. CPA + MF; $\mathrm{p}<0.01)$. Following administration of CPA $(150 \mathrm{mg} / \mathrm{kg}$, s.c.), the number of regenerative crypts was similar to that of the normal group $(117.8 \pm 14.9$ vs. $107.4 \pm 9.7)$, but treatment with MAK caused a significant up-regulation compared with the CPA-alone group $(130.4 \pm 13.8$ to $160.4 \pm 17.1$, a $10.7-36.2 \%$ increase vs. CPA $+\mathrm{MF} ; \mathrm{p}<0.01)$. The number of regenerative crypts after the administration of Iressa $(2,000 \mathrm{mg} / \mathrm{kg}$, p.o.) was similar to that of the normal group (107.5 \pm 11.7 vs. 108.0 \pm 13.9$)$, but the Iressa + MAK group showed a significant up-regulation compared with the Iressa-alone group $(117.8 \pm 10.6$ to $123.6 \pm 14.7$, a 9.6-15.0\% increase vs. Iressa $+\mathrm{MF}$; $\mathrm{p}<0.01)$. Similarly, the number of regenerative crypts was unaffected by the administration of Iressa $(4,000 \mathrm{mg} / \mathrm{kg}$, p.o.) $(110.0 \pm 11.8$ vs. $110.5 \pm 12.6$ in the normal group), but was significantly up-regulated in the Iressa + MAK group compared with the Iressa-alone group $(132.2 \pm 15.5$ to $161.5 \pm 19.8$, a $20.2-46.8 \%$ increase vs. Iressa + $\mathrm{MF} ; \mathrm{p}<0.01)$.

Histologically, no marked changes such as desquamation, edema and/or necrosis were noted in the small intestine following the administration of CPA or Iressa.

\section{Discussion}

MAK prevented small intestinal injury by increasing the number of regenerative crypts, but had no effect on body weight loss induced by 5FU, UFT and CDDP. Wang et al reported that a G. lucidum extract ameliorated CDDP-induced nausea, vomiting and food intake in a concentration-dependent manner in a rat pica model measuring kaolin intake (15). In a clinical study reported by Shu-Ru et al, a Chinese medicinal herb complex containing a G. lucidum extract decreased leucopenia and neutropenia induced by chemotherapy and/or radiotherapy (16). Nonaka et al reported that an antlered form of G. lucidum (Rokkaku-reishi) relieved CPA-induced weight loss, and suggested that G. lucidum is useful in reducing the adverse effects of anti-cancer drugs (17). Furthermore, Nonaka et al reported that G. lucidum inhibited transplanted tumor growth, elongated life span when administered orally to mice (18) and showed anti-tumor activity when administered after tumor inoculation.

Recently, we found that $5 \mathrm{FU}$ decreased the formation of aberrant crypt foci (ACF) induced by azoxymethane, and that combination with MAK further decreased the number of ACF (19). We suggested that MAK reduces the gastrointestinal adverse effects of anti-cancer drugs without attenuating their beneficial anti-tumor activity.

In the present experiment, MAK attenuated small intestinal damage caused by 5FU, whereas AGA did not. Further studies are required to elucidate the difference in the effects of mycelia and fruiting bodies, although we noted earlier that AGA does not protect against small intestinal damage by X-irradiation. We conclude that AGA is ineffective for the prevention of acute small intestinal injury. On the other hand, the present study showed that MAK is active against small intestinal injury induced by 5FU, UFT, CPA, Iressa and CDDP.

It is well established that, regardless of the administration route, the mechanism by which anti-cancer drugs such as $5 \mathrm{FU}$,
UFT and CDDP exert both their therapeutic and toxic effects is by inhibition of DNA synthesis. Recently, Tong et al reported that Reishi increased the uptake of BrdU in a mouse spleen cell cultivation system and promoted cell proliferation (20). In our study, the number of regenerative crypts increased by administration of CPA or Iressa plus MAK, but not of MAK alone. Furthermore, we observed no marked changes such as desquamation, edema and/or necrosis in the small intestine after administration of CPA or Iressa. Clinically, small intestinal injury was reported after administration of both CPA and Iressa (21). The reason that these two anti-cancer drugs did not affect small intestinal crypts in this experiment is not clear, but it is conceivable that they had some effect other than inhibition of DNA synthesis, since crypt regeneration was accelerated by MAK after administration of these agents. It is possible that MAK-induced crypt regeneration after administration of these drugs is a response to a mild injury that cannot be detected by microscopic observation.

Taken together, the results suggest that Reishi can immediately promote cell growth to repair acute injury caused by trauma such as X-irradiation and/or administration of chemotherapeutic drugs. Recently, Fukatsu et al reported that 5FU influences gut-associated lymphoid tissue (known as GALT) by reducing the number of lymphocytes in the small intestinal intraepithelial space and lamina propria (22). Strober et al reported that the breakdown of GALT may contribute to chronic inflammatory bowel disease, such as Crohn's disease and ulcerative colitis (23). Previously, we found that MAK shows a preventive action on the DSS-induced mouse model of ulcerative colitis (unpublished data). In this context, the acceleration of regenerative crypt growth after administration of 5FU, UFT, CPA and Iressa suggests that MAK functions through a GALT-mediated mechanism of action. It is thought that a part of the activity of Rokkaku-reishi against the adverse effects of CPA may be mediated by its immunomodulating properties, such as natural killer activity, interferon- $\gamma$ production, cytotoxic T-lymphocyte activity and inhibition of abnormal changes in the interleukin-4 level $(17,18)$. We also previously reported that MAK has immunomodulating functions, such as the up-regulation of phagocytosis and NK activity and increased TNF- $\alpha$ production (24). Thus, if the administration of anti-cancer drugs such as CPA and Iressa induces immunological dysregulation in the GALT, such effects may be reversed by the immunomodulatory action of MAK.

Edema or cell infiltration of the fore-stomach and/or renal injury after administration of anti-cancer drugs were confirmed by the microscopic observations in this experiment, although MAK appeared to have little effect on these lesions (data not shown). Conversely, Omori et al reported that Reishi reduced the renal disorder induced by CDDP (25). However, our study only had 3.5 day duration and the longer-term effect of MAK on injury to these organs needs to be established in further studies.

In conclusion, our results suggest that MAK ameliorates the small intestinal damage induced by cancer treatments such as radiotherapy and chemotherapy, thereby improving the quality of life of cancer patients. Further studies of longer duration are required to assess the value of this preparation in the treatment of other adverse effects of anti-cancer drugs, such as organ injury and alopecia. 


\section{References}

1. Lin ZB: Pharmacological functions of Ganoderma lucidum. In: Modern Research of Ganoderma Lucidum. Lin ZB (ed). 2nd edition. Beijing Medical University Press, pp284-309, 2001.

2. Wasser SP and Weis AL: Medicinal properties of substances occurring in higher basidiomycetes mushrooms: current perspective. Int J Med Mushrooms 1: 31-62, 1999.

3. Shiao MS: Natural products of the medicinal fungus Ganoderma lucidum: occurrence, biological activities and pharmacological functions. Chem Rec 3: 172-180, 2003.

4. Hu H, Ahn NS, Yang X, Lee YS and Kang KS: Ganoderma lucidum extract induces cell cycle arrest and apoptosis in MCF-7 human breast cancer cell. Int J Cancer 102: 250-253, 2002.

5. Sliva D, Labarrere C, Slivova V, Sedlak M, Lloyd FP Jr and Ho NW: Ganoderma lucidum suppresses motility of highly invasive breast and prostate cancer cells. Biochem Biophys Res Commun 298: 603-612, 2002.

6. Ghafar MA, Golliday E, Bingham J, Mansukhani MM, Anastasiadis AG and Katz AE: Regression of prostate cancer following administration of genistein combined polysaccharide $\left(\mathrm{GCP}^{\mathrm{TM}}\right)$, a nutritional supplement: a case report. J Altern Complement Med 8: 493-497, 2002.

7. Gao Y, Zhou S, Jiang W, Huang M and Dai X: Effects of ganopoly (a Ganoderma lucidum polysaccharide extract) on the immune functions in advanced-stage cancer patients. Immunol Invest 32: 201-215, 2003.

8. Song YS, Kim SH, Sa JH, Jin C, Lim CJ and Park EH: Anti-angiogenic and inhibitory activity on inducible nitric oxide production of the mushroom Ganoderma lucidum. J Ethnopharmacol 90: 17-20, 2004.

9. Lakshmi B, Ajith TA, Sheena N, Gunapalan N and Janardhanan KK: Antiperoxidative, anti-inflammatory and antimutagenic activities of ethanol extract of the mycelium of Ganoderma lucidum occurring in South India. Teratog Carcinog Mutagen 1: 85-97, 2003.

10. Lu H, Uesaka T, Katoh O, Kyo E and Watanabe H: Prevention of the development of preneoplastic lesions, aberrant crypt foci, by a water-soluble extract from cultured medium of Ganoderma lucidum (Rei-shi) mycelia in male F344 rats. Oncol Rep 8: 1341-1345, 2001.

11. Lu H, Kyo E, Uesaka T, Katoh $\mathrm{O}$ and Watanabe $\mathrm{H}$ : Prevention of development of N,N'-dimethylhydrazine-induced colon tumors by a water-soluble extract from cultured medium of Ganoderma lucidum (Rei-shi) mycelia in male ICR mice. Int J Mol Med 9: 113-117, 2002.

12. Lu H, Kyo E, Uesaka T, Katoh $\mathrm{O}$ and Watanabe H: A watersoluble extract from cultured medium of Ganoderma lucidum (Rei-shi) mycelia suppresses azoxymethane-induction of colon cancers in male F344 rats. Oncol Rep 10: 375-379, 2003.

13. Kashimoto N, Hayama M, Kamiya $\mathrm{K}$ and Watanabe $\mathrm{H}$ : Inhibitory effect of a water-soluble extract from the culture medium of Ganoderma lucidum (Rei-shi) mycelia on the development of pulmonary adenocarcinoma induced by N-nitrosobis (2-hydroxypropyl) amine in Wistar rats. Oncol Rep 16 1181-1187, 2006.
14. Kubo N, Myojin Y, Shimamoto F, Kashimoto N, Kyo E, Kamiya $\mathrm{K}$ and Watanabe $\mathrm{H}$ : Protective effects of a water-soluble extract from cultured medium of Ganoderma lucidum (Rei-shi) mycelia and Agaricus blazei Murrill against X-irradiation in B6C3F1 mice: increased small intestinal crypt survival and prolongation of average time to animal death. Int J Mol Med 15: 401-406, 2005.

15. Wang CZ, Basila D, Aung HH, Mehendale SR, Chang WT, McEntee E, Guan X and Yuan CS: Effects of Ganoderma lucidum extract on chemotherapy-induced nausea and vomiting in a rat model. Am J Chin Med 33: 807-815, 2005.

16. Zhuang SR, Chen SL, Tsai JH, Huang CC, Wu TC, Liu WS, Tseng HC, Lee HS, Huang MC, Shane GT, Yang CH, Shen YC, Yan YY and Wang CK: Effect of citronellol and the Chinese medical herb complex on cellular immunity of cancer patients receiving chemotherapy/radiotherapy. Phytother Res 23: 785-790, 2009.

17. Nonaka Y, Ishibashi H, Nakai M, Shibata H, Kiso Y and Abe S: Soothing effect of Ganoderma lucidum antlered form on cyclophosphamide-induced adverse reaction. Jpn J Cancer Chemother (in Japanese) 32: 1586-1588, 2005.

18. Nonaka Y, Ishibashi H, Nakai M, Shibata H, Kiso Y and Abe S: Effects of the antlered form of Ganoderma lucidum on tumor growth and metastasis in cyclophosphamide-treated mice. Biosci Biotechnol Biochem 72: 1399-1408, 2008.

19. Kashimoto K, Ishii S, Nishihama T, Yanagida M, Hayama M and Watanabe H: Effects of a water-soluble extract of Ganoderma lucidum mycelia (MAK) on ACF and crypt survival by 5-FU in F344 rats. 67th Annual Meeting of the Japanese Cancer Association Proceedings, p383, 2008.

20. Tong MH, Chien PJ, Chang HH, Tsai MJ and Sheu F: High processing tolerances of immunomodulatory proteins in Enoki and Reishi mushrooms. J Agric Food Chem 56: 3160-3166, 2008.

21. Inomata S, Takahashi H, Nagata M, Yamada G, Shiratori M, Tanaka H, Satoh M, Saitoh T, Sato T and Abe S: Acute lung injury as an adverse event of gefitinib. Anticancer Drugs 15: 461-467, 2004.

22. Fukatsu K, Nagayoshi H, Maeshima Y, Ueno C, Saitoh D and Mochizuki H: Fish oil infusion reverses 5-fluorouracil-induced impairments in mucosal immunity in mice. Clin Nutr 27: 269-275, 2008

23. Strober W, Fuss IJ and Blumberg RS: The immunology of mucosal models of inflammation. Annu Rev Immunol 20: 495-549, 2002.

24. Kashimoto N, Kyo E, Uesaka T, Katoh O and Watanabe H: Immunomodulation and antitumor activities of a water soluble extract from cultured medium of Ganoderma lucidum (Reishi) mycelia. J Jpn Mibyo Sys Assoc (in Japanese) 9: 293-296, 2003.

25. Ohmori K, Ito M, Kishi M, Mizutani H, Katada T and Konishi $\mathrm{H}$ : Effect of Reishi mushroom on side effects induced by CDDP. Biotherapy (in Japanese) 9: 95-98, 1995. 